\title{
Satellite passive microwave observations and analysis of Arctic and Antarctic sea ice, 1978-1987
}

\author{
Per Gloersen, \\ Laboratory for Hydrospheric Processes, NASA Goddard Space Flight Center, Greenbelt, MD 20771, U.S.A. \\ William J. CAMPBell, \\ United States Geological Survey, Ice and Climate Project, University of Puget Sound, Tacoma, WA 98416, U.S.A. \\ Donald J. Cavalieri, Josefino C. Comiso, Claire L. Parkinson and H. Jay Zwally \\ Laboratory for Hydrospheric Processes, NASA Goddard Space Flight Center, Greenbelt, MD 20771, U.S.A.
}

\begin{abstract}
We have recently completed an analysis that examines in detail the spatial and temporal variations in global sea-ice coverage from 26 October 1978, through 20 August 1987. The sea-ice measurements we analyzed are derived from data collected by a multispectral, dual-polarized, constant incidence-angle microwave imager, the Scanning Multichannel Microwave Radiometer (SMMR) on board the NASA Nimbus 7 satellite. The characteristics of the SMMR have permitted a more accurate calculation of total sea-ice concentrations (fraction of ocean area covered by sea ice) than earlier single-channel instruments and, for the first time, a determination of both multiyear sea-ice concentrations and physical temperatures of the sea-ice pack. An estimate of the SMMR wintertime total ice concentration accuracy of $\pm 7 \%$ in both hemispheres has been obtained. As this is an improvement over the estimated accuracies of previous microwave sensors, we are able to present improved calculations of the sea-ice extents (areas enclosed by the $15 \%$ ice concentration boundaries), sea-ice concentrations, and open-water areas within the ice margins. This analysis will be published in a book, Arctic and Antarctic sea ice, 1978-1987: satellite passive microwave observations and analysis, due for publication in 1992. Some highlights from the analysis are presented in this paper.
\end{abstract}

\section{INTRODUCTION}

This paper provides a brief description of spatial and temporal variations in Arctic and Antarctic sea-ice covers from 26 October 1978 through 20 August 1987, based on data collected by the Scanning Multichannel Microwave Radiometer (SMMR) on board the NASA Nimbus 7 satellite. A more comprehensive description and analysis of these events appear in a book, due to be published in 1992 (Gloersen and others, 1992). The book includes an analysis of color plate maps of monthly average sea-ice concentrations and their anomalies from November 1978 through August 1987 and a time series of both monthly averaged and single-day (usually on two-day intervals) SMMR sea-ice data. This 8.8-year period, together with the four years of the Nimbus 5 Electrically Scanning Microwave Radiometer (ESMR) observations presented in two earlier volumes (Zwally and others, 1983; Parkinson and others, 1987), comprises a sea-ice record spanning almost 15 years.

SMMR measures vertically and horizontally polarized radiances at five wavelengths ranging from $0.81 \mathrm{~cm}$ to $4.5 \mathrm{~cm}$, providing a total of ten channels of radiance data. The spatial resolution of the SMMR varies with wavelength and ranges from 30 to $150 \mathrm{~km}$. The 0.8 - and $1.7-\mathrm{cm}$ channels are utilized for calculating ice concentrations and have integrated fields of view of 30 and $55 \mathrm{~km}$, respectively. The $55 \mathrm{~km}$ spatial resolution of the SMMR ice concentrations is maintained by mapping the SMMR radiances onto a polar stereographic projection with a grid spacing of about $25 \mathrm{~km}$.

The SMMR sea-ice measurements represent a distinct improvement over the Nimbus 5 data used for the earlier books. The ESMR was a single-channel instrument with cross-track scanning and varying incidence angle, whereas the SMMR was a multichannel, dual-polarized, constant incidence-angle microwave imager. The multichannel, constant incidence-angle characteristics of the SMMR have permitted a more accurate calculation of total sea-ice concentrations (fraction of ocean area covered by sea ice) and, for the first time, determination of both multiyear sea-ice concentrations and the physical temperatures of the sea-ice pack (Cavalieri and others, 1984; Gloersen and Cavalieri, 1986). An overall accuracy of $\pm 7 \%$ for the SMMR total ice concentrations in both hemispheres compares with an estimated $\pm 25 \%$ accuracy for the ESMR in the Arctic and $\pm 15 \%$ for the Antarctic (Gloersen and others, 1992). The improved 
accuracy of SMMR ice concentrations permits more accurate calculations of the sea-ice extents (sum of all map areas that are covered by $15 \%$ or more of sea ice), sea-ice areas (sum of the map areas weighted by the ice concentration in each), and ice-free areas within the ice margins (the difference between the ice extents and areas).

\section{ICE COVERAGE IN THE ARGTIC}

For the purpose of examining regional differences, the Arctic was divided into nine regions (Gloersen and others, 1992). Analysis of the Arctic SMMR time-series for the sum of these regions reveals that the Arctic seasonal cycle of the ice extent ranges, on average, from a minimum of $9 \times 10^{6} \mathrm{~km}^{2}$ in September to a maximum of $16 \times 10^{6} \mathrm{~km}^{2}$ in March (Fig. 1), with the Arctic Ocean region contributing about $14 \%$ of the $3.5 \times 10^{6} \mathrm{~km}^{2}$ amplitude, the balance being contributed by the perimeter seas. The interannual variability of the ice extents is much larger for the individual regions than for the Arctic as a whole, with some regions exhibiting decreasing trends and others increasing. Negative trends
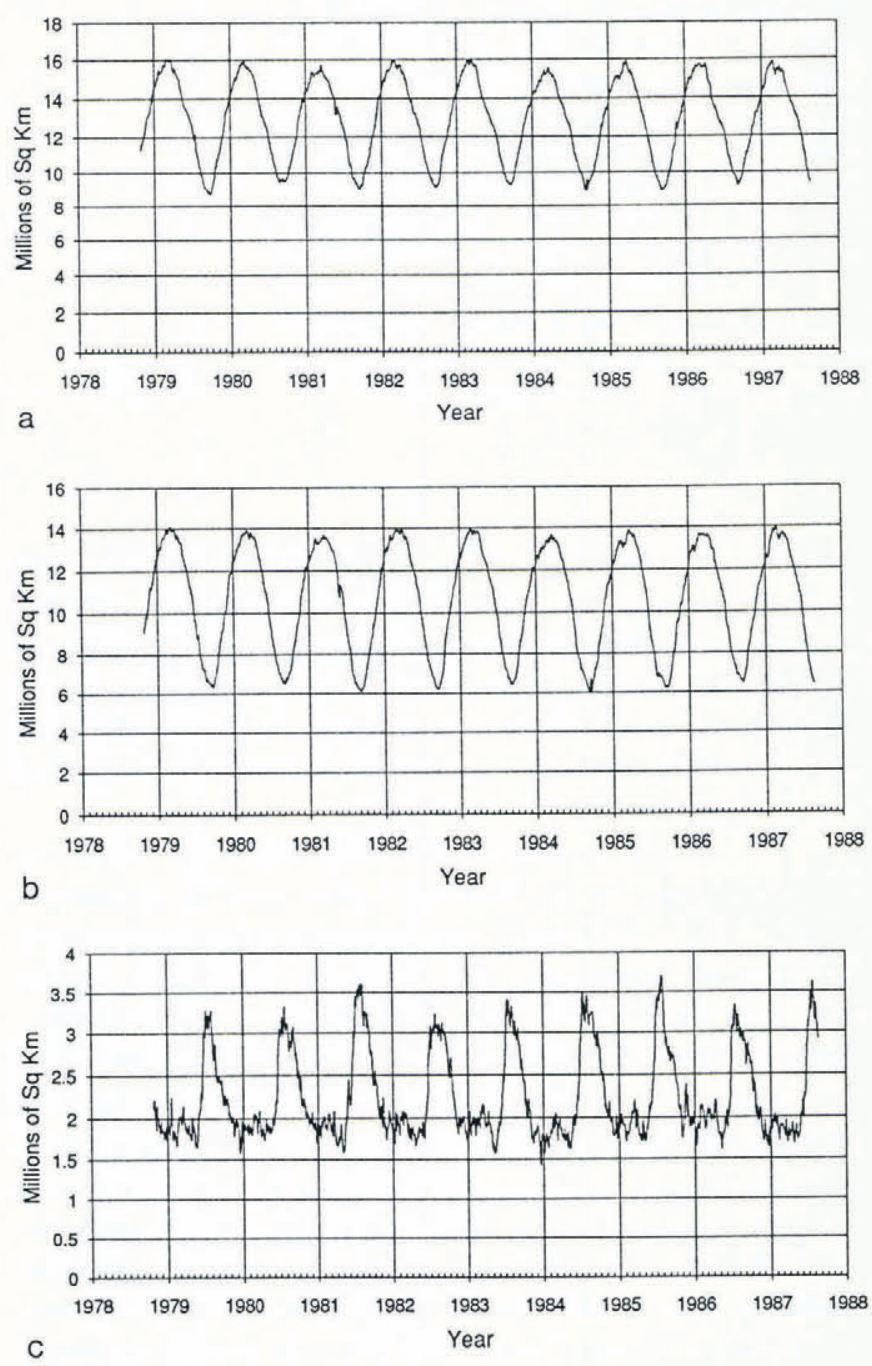

Fig. 1. (a) Sea-ice extent, (b) sea-ice area, and (c) amount of open water within the pack for the Arctic from 26 October 1978 to 20 August 1987. in the Sea of Okhotsk, the Greenland Sea and the Kara and Barents seas were countered in part by positive trends in the Arctic Ocean, Bering Sea, Hudson Bay, and Baffin Bay, Davis Strait and Labrador Sea, resulting in a small but statistically significant net negative trend ($2.1 \pm 0.9 \%$ ) over the 8.8 year record. Ice-free (open water) areas within the ice pack (Fig. 1) were also found to have a negative trend $(-3.5 \pm 2.0 \%)$. The confidence level for each of these trends is better than $90 \%$ (Gloersen and Campbell, 1991).

The 8.8 year SMMR record reveals that the Arctic Ocean ice pack at the end of the summer melt season usually assumes either of two different positions. One of these, called the Siberian mode, is characterized by the ice pack being separated from the Alaskan coastline, leaving extensive open water areas along its shoreline. The other, the Alaskan mode, is characterized by the ice pack impinging on or being close to the Alaskan coastline. This phenomenon is readily apparent in the September maps of sea ice concentration (Gloersen and others, 1992). A relationship between this bimodal behavior of summer ice distribution and general Arctic oceanic circulation patterns can be inferred from the Arctic Ocean Buoy Program (AOBP) data. The Siberian mode occurs when the general circulation pattern assumes its long-term state, i.e., with a well-developed Beaufort Gyre and Transpolar Drift Stream. The Alaskan mode occurs when the long-term state breaks down. These two modes are evenly divided over the 1979-87 time span, with one of the years (1981) having a rather amorphous ice distribution. This contrasts with the earlier ESMR years when the Siberian mode persisted for three of the four years.

The higher accuracy of SMMR ice concentrations has increased the confidence in the observation of areas of reduced concentration (polynyas) that occur in the Arctic Ocean from November through April. These polynya areas have typical lifetimes the order of months, not days or weeks as have summer polynya areas. Zones where they occur most often are the southern Beaufort Sea adjacent to the McKenzie Delta and Alaskan coast, near the center of the usual location of the Beaufort Gyre, and along the Siberian side of the Transpolar Drift Stream, as can be seen in the monthly average color maps of ice concentration for February, and in some single-day color maps selected in the interval 11 September 1986 to 1 December 1987 (Gloersen and others, 1992). These winter polynyas do not form in each zone each winter.

Time series of sea-ice extent and sea-ice area in the Greenland Sea (one of the nine regions) are shown in Figure 2. The amplitude of the seasonal cycle varies by as much as $60 \%$ during the 9 -year period, with the smallest peak occurring in 1984, the year without the "Odden", so named by ancient Norse mariners. The Odden is a protuberance of sea ice in the East Greenland Current that extends several hundred $\mathrm{km}$ into the Greenland Sea, sometimes to the east of the Greenwich Meridian. Under the appropriate atmospheric conditions, it appears in the cold waters transported away from Greenland in an oceanic current pattern known as the Jan Mayen Gyre. The sudden occurrence of the Odden has been reported for centuries by Scandinavian fisherman and sealers. The Odden appears in all years of SMMR operations except 

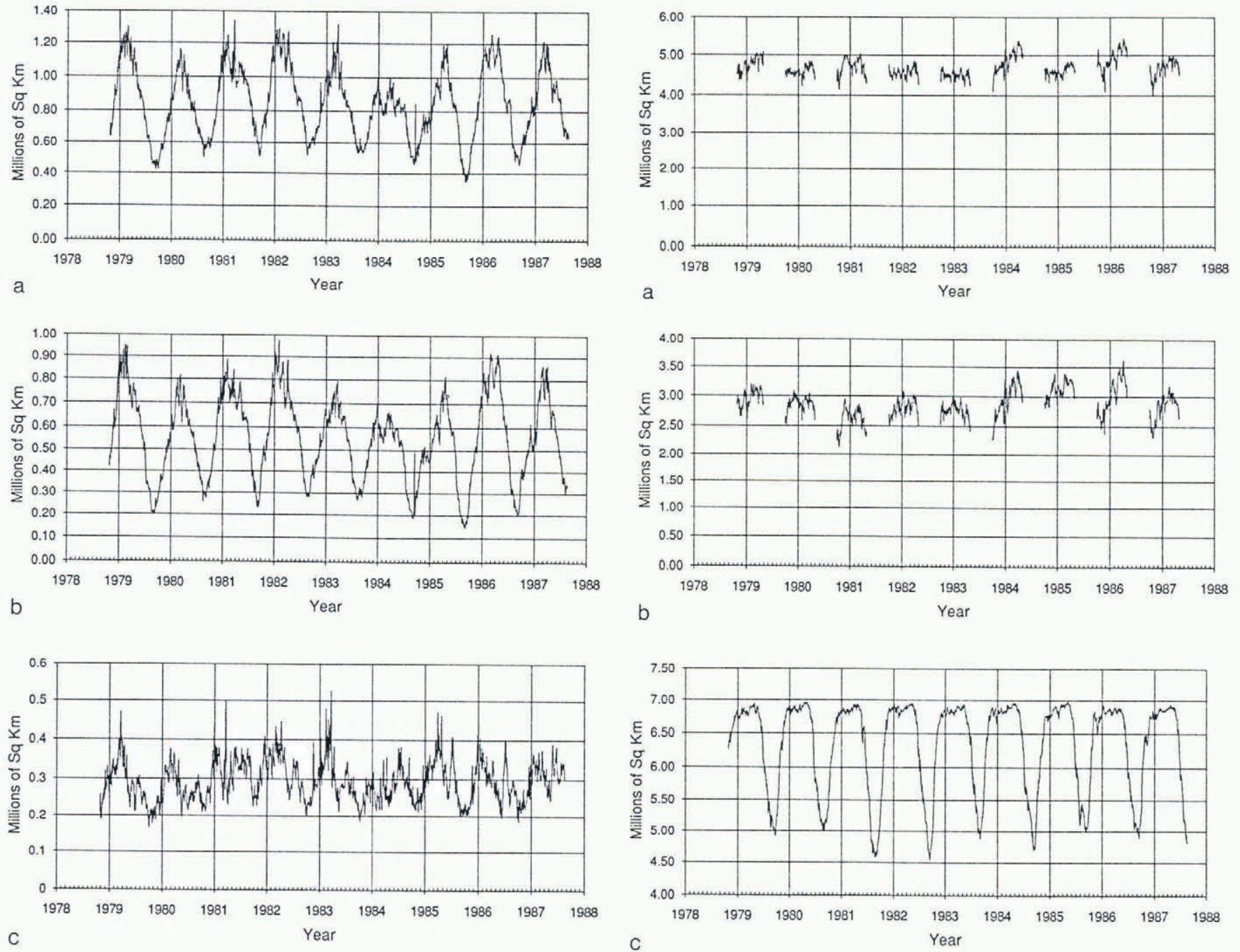

Fig. 2. (a) Sea-ice extent, (b) sea-ice area, and (c) amount of open water within the pack for the Greenland Sea from 26 October 1978 to 20 August 1987.

1984, and shows considerable interannual variability. Its absence in 1984 is probably a result of unusually warm local weather conditions, but this conjecture remains to be substantiated. There appears to be a slow oscillation in the amplitude of the peaks in Figure 2, with a period of about four years. On a shorter time scale, there appears to be an oscillation with a period of about two to three months, superimposed on the annual cycle. The 8.8-year record of ice-free areas within the pack in the Greenland Sea (Fig. 2) shows a remarkable lack of seasonal signal, the areas of open water generally being in the range of 2$4 \times 10^{5} \mathrm{~km}^{2}$.

\section{MULTIYEAR SEA ICE IN THE ARGTIG}

Multispectral radiances from the SMMR have permitted for the first time mapping the multiyear sea-ice distribution within the central Arctic during the winter months without the first-year/multiyear ice type ambiguity. The multiyear ice distribution in winter is characterized by concentrations as high as $96-100 \%$ north of the Canadian Archipelago and by lower and more variable concent-

rations in other regions of the central Arctic. The average multiyear ice concentration in the perennial pack is about $60 \%$. The accuracy of the derived multiyear ice concentrations is estimated to be about $11 \%$ (Gloersen and others, 1992).

The SMMR record shows widely different distributions of the multiyear sea ice from year to year, and occasional sudden redistribution during the course of a given winter. Ordered motion of the pack is also indicated by seasonal multiyear ice concentration difference maps (Gloersen and others, 1992). Time series of the multiyear ice area and extent (the sum of map areas with more than $20 \%$ multiyear ice), along with total ice area for the Arctic Ocean, are shown in Figure 3. There is no consistent correlation between the area of ice at the iceextent minimum in mid-September and the multiyear area the following winter. Also, there is a marked difference between the magnitudes of these two areas. The SMMR record indicates that only about $60 \%$ of the ice area at the mid-September ice minima become multiyear ice each year. Much of the difference is explained by the fact that the ice at the mid-September minimum includes not only ice that becomes multiyear 
ice the following winter, but also some new ice that persists into the winter as first-year ice, and some ice that will melt prior to the winter season. To demonstrate this, a local least-ice area map has been produced for June through October of 1981 (Gloersen and others, 1992), to compare with the mid-September minimum area of $4.6 \times 10^{6} \mathrm{~km}^{2}$ (Fig. 3). The sum of these minimum ice areas, occurring at different times within the specified interval in 1981 , is $3.4 \times 10^{6} \mathrm{~km}^{2}$, compared to a multiyear ice area of $2.8 \times 10^{6} \mathrm{~km}^{2}$ the following winter. The remaining difference, larger than allowed by the estimated $11 \%$ accuracy, is attributed mostly to the lack of coincidence between the area enclosed by the perimeter of the summer composite minimum and that of the subsequent multiyear ice extent.

\section{SEA-ICE GOVERAGE IN THE ANTARCTIC}

In winter, sea ice extends as far as $2200 \mathrm{~km}$ from the Antarctic continent, covering approximately $19 \times 10^{6}$ $\mathrm{km}^{2}$ of the Southern Ocean. In contrast to much of the Arctic sea-ice pack, the Antarctic pack has an outer boundary unconstrained by land. Further, the Antarctic sea-ice pack is subject to strong circumpolar winds that produce, on average, an outward stress component on the sea ice. Consequently, the Antarctic sea-ice cover is generally more divergent than much of the Arctic ice cover. Greater divergence of the ice pack produces a larger amount of open water and thin ice. Within the winter Antarctic ice pack, open water covers about 21\% of the total area at maximum ice extent (Fig. 4). The lowest ice concentrations are located in the outer margin of the ice pack and in numerous coastal polynyas around the continent, where drainage winds from the ice sheet force frequent changes in ice concentration (Gloersen and others, 1992). In the Weddell Sea, a very large $\left(0.25 \times 10^{6} \mathrm{~km}^{2}\right)$ polynya, called the Weddell polynya, persisted during the winters of 1974, 1975, and 1976 (Zwally and others, 1983), but has not been observed during the SMMR period.

Southern Ocean sea ice (see Fig. 4) typically has minimum sea-ice extent in February. This minimum is followed by expansion of the ice cover until the maximum coverage is attained sometime in August, September, or October, and then by a rapid decay from November through December. For the purpose of analyzing interregional differences, the Southern Ocean is divided into five sectors (Gloersen and others, 1992). During February to March, growth of ice extent and area occur mainly in the Ross and Weddell Seas, while their decay continues near the outer margin of much of the ice pack, especially in the Bellingshausen and Amundsen Seas and Indian Ocean sectors. The most rapid expansion of the ice cover occurs during the period from March to June. The ice growth from February to March is more rapid in the Ross Sea than in the other four sectors. In the Weddell Sea, expansion of the ice cover during autumn is predominantly eastward, compared to a predominantly northward expansion elsewhere. During July to August, while ice growth is occurring throughout most of the ice pack, some decreases in ice concentration occur, mainly in the Weddell Sea and the inner Ross Sea.
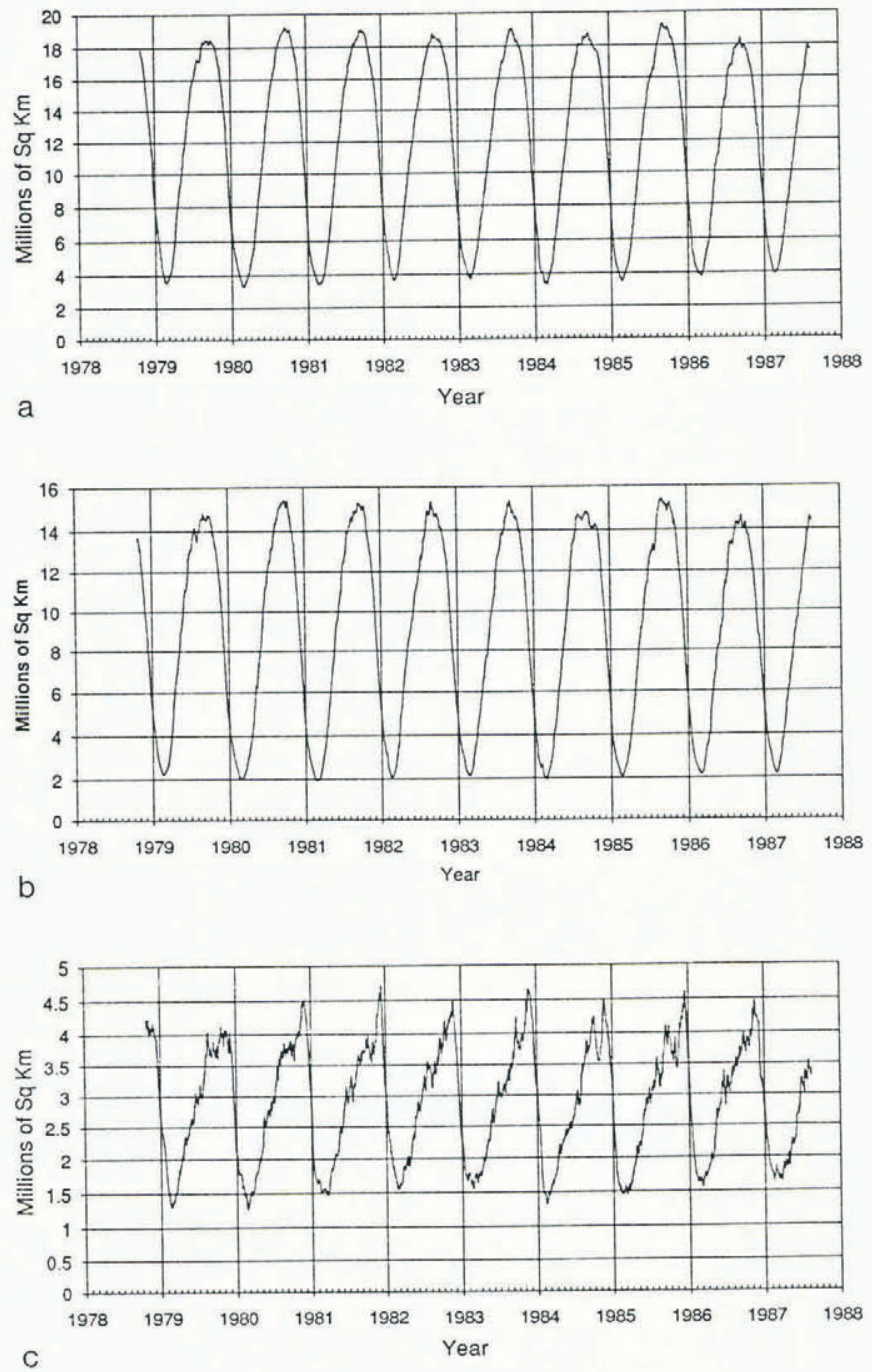

Fig. 4. (a) Sea-ice extent, (b) sea-ice area, and (c) amount of open water within the pack for the Antarctic from 26 October 1978 to 20 August 1987.

Over the SMMR observation period, the ice extent during September varies between 18.2 and $19.2 \times 10^{6} \mathrm{~km}^{2}$, and the ice area varies between 14.2 and $15.2 \times 10^{6} \mathrm{~km}^{2}$ (Fig. 4). These values indicate an interannual variability in the winter ice cover of $\pm 5 \%$ in both ice extent and ice area during these years. The difference of these two, the open water within the pack, varies from about $3.8 \times 10^{6} \mathrm{~km}^{2}$ to about $4.6 \times 10^{6} \mathrm{~km}^{2}$ (Fig. 4). Open water maxima persist from September to December, and represent about $21 \%$ of the area of ice extent during that period.

The amplitude of the average seasonal cycle in the Antarctic ice extent is about $8 \times 10^{6} \mathrm{~km}^{2}$ with a seasonal minimum of $3.5 \times 10^{6} \mathrm{~km}^{2}$ and a seasonal maximum of $19 \times 10^{6} \mathrm{~km}^{2}$ (Fig. 4). As in the Arctic, individual sectors have larger interannual differences than the Antarctic as a whole, implying compensating relationships in the various regions (Gloersen and others, 1992). For instance, a seven-year undulation in the sea-ice extent maxima of the Weddell, Amundsen, and Bellingshausen Seas is countered by a similar but out-of-phase undulation in the Western Pacific. Although ice extents in the Weddell 

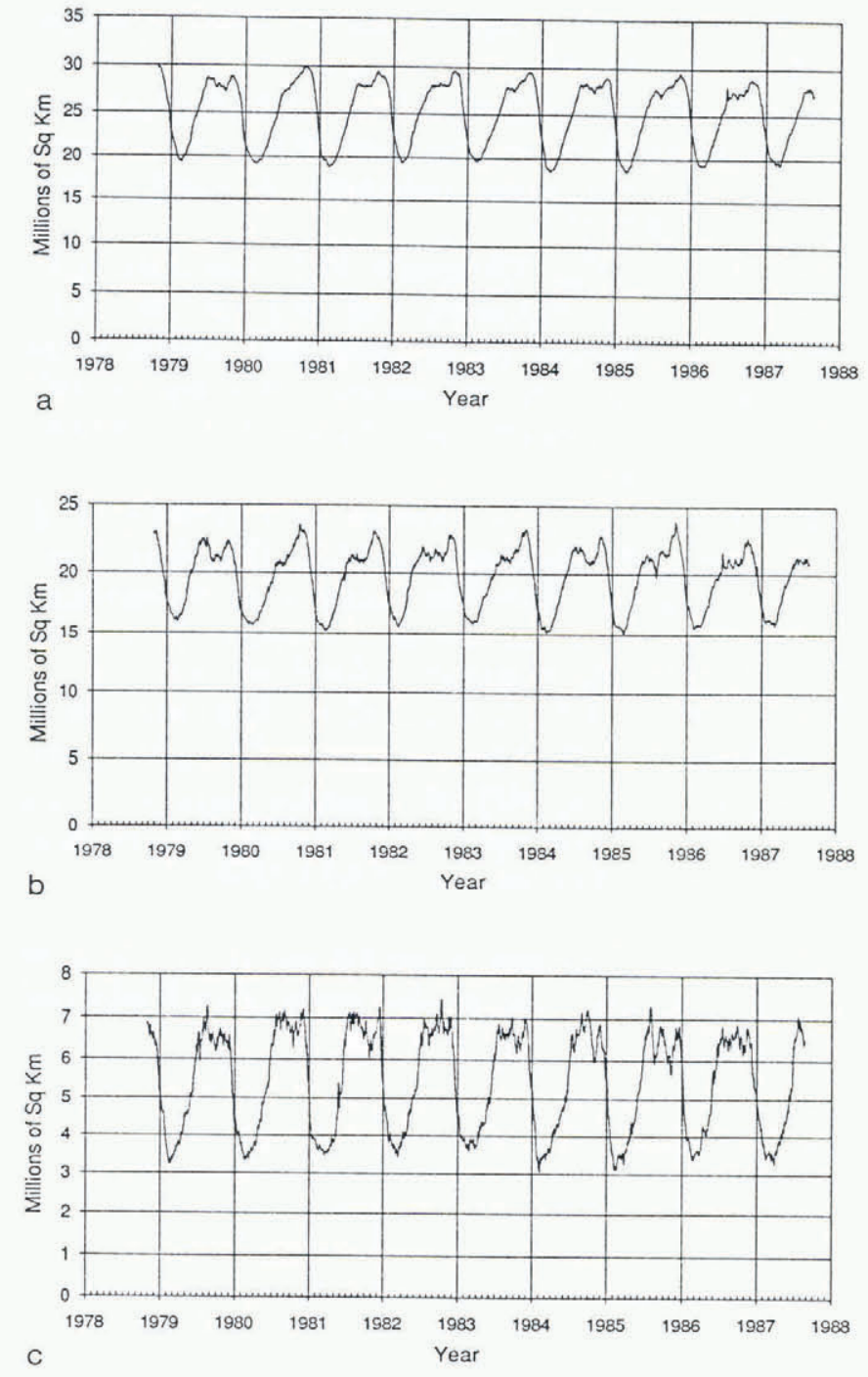

Fig. 5. Global (a) sea-ice extent, (b) sea-ice area, and (c) amount of open water within the pack from 26 October 1978 to 20 August 1987.

Sea have a large downward trend during the 8.8-year SMMR record, this is countered by positive trends in the Ross Sea and Indian Ocean. The result for the Antarctic as a whole is a time series of ice extents with no statistically significant trend (Gloersen and Campbell, 1991).

\section{GLOBAL ASPEGTS OF SEA-ICE COVERAGE}

Variations in Arctic and Antarctic sea-ice extents and areas shown in Figures 3 and 4 for the 8.8-year SMMR record have been summed to provide the global curves in Figure 5. For each of these variables, the minimum of the global seasonal oscillations coincides closely with the minimum in the Antarctic sea-ice extent and area, which falls within a few days of 25 February every year. The global extent maxima are broader than those of the individual hemispheres and have double peaks, with the valley between them occurring at approximately the same times as the Arctic minima.

Globally, seasonal amplitude of the combined Arctic and Antarctic sea-ice extent varies from a minimum of about $20 \times 10^{6} \mathrm{~km}^{2}$ to a maximum of about $30 \times 10^{6} \mathrm{~km}^{2}$ and is roughly in phase with the Antarctic oscillation. The $2.1 \%$ negative trend in the Arctic sea-ice extent, combined with a lack of a similar trend in the Antarctic, results in an overall negative trend of about $1 \%$ in global sea ice during the SMMR lifetime.

The global ice area varies seasonally by as much as $40 \%$ of the mean (Fig. 5) and this variation represents an annual change of about $10^{24} \mathrm{~J}$ in the amount of latent heat stored in the global sea ice, assuming a constant average ice thickness in the seasonal ice zones of $0.5 \mathrm{~m}$. The seasonal variation in the areas of open water within the pack on the global scale (Fig. 5) is about $80 \%$ of their mean. Since there can be a two to three order-ofmagnitude difference in the rate of sensible heat exchange between the atmosphere and the ocean surface in the winter depending on whether ice exists on the surface or not (Badgley, 1966; Maykut, 1978), annual fluctuations in the global sea-ice area can play a significant role in global atmospheric circulation (Budd, 1975; Simmons and Budd, 1990).

\section{SEA-ICE TEMPERATURES}

Monthly averaged ice temperatures derived from the SMMR data are also presented as color maps (Gloersen and others, 1992). The SMMR ice temperatures are based primarily on the vertically-polarized $4.5 \mathrm{~cm}$ radiation, which is relatively insensitive to ice type. While not validated, the SMMR sea-ice temperature data provide information not available from any other source, and may be potentially useful for surfaceatmosphere heat transfer studies in the polar regions. The SMMR and the AOBP temperature data sets have important differences in their interpretation. The AOBP temperatures are point measurements that closely match surface-air temperatures in winter. In contrast, the SMMR ice temperatures are a spatially averaged measure of the temperature of the radiating portion of the ice, typical of the snow-ice interface for first-year ice and of a weighted-mean temperature of the freeboard layer for multiyear ice. A linear regression analysis of the wintertime SMMR and AOBP temperatures (Gloersen and others, 1992) shows the SMMR temperatures to be $5 \mathrm{~K}$ to $13 \mathrm{~K}$ warmer, on average, with the larger biases over regions of thick multiyear ice. The standard error of estimate between the two data sets is $4.7 \mathrm{~K}$.

\section{CONCLUDING REMARKS}

The SMMR sea-ice book previewed here will be complemented by a series of 12 CD-ROMs containing the 8.8 year SMMR polar data set. These CD-ROMs are being made available by Goddard Space Flight Center and are archived at and distributed by the National Snow and Ice Data Center (NSIDC) in Boulder, Colorado. They contain brightness temperature and ice concentration maps for every other day, all on the same polar stereographic grids used in Gloersen and others (1992). The radiance data are for eight of the ten horizontally and vertically polarized channels, with the $1.4-\mathrm{cm}$ 
channels not included because of severe instrument drift. An additional CD-ROM is planned that will contain also monthly averaged ice concentrations, ice temperatures, and other data as they appear in Gloersen and others (1992). Similar brightness temperature and sea-ice concentration maps are being created and distributed on CD-ROMs by NSIDC for the Defense Meteorological Satellite Program Special Sensor Microwave Imager (SSMI.). A comparison has shown that seaice concentration differences (SMMR-SSMI) during the two months of overlap are $0.2 \% \pm 2.5 \%$ during austral winter and $0.5 \% \pm 5 \%$ during boreal summer. This measure of consistency between the two data sets should encourage the use of the combined data sets, which provide well over a decade of global multispectral passive microwave observations.

\section{REFERENGES}

Cavalieri, D.J., P. Gloersen and W.J. Campbell. 1984. Determination of sea ice parameters with the NIMBUS 7 SMMR. 7. Geophys. Res., 89(D4), 5355-5369.

Gloersen, P. and W.J. Campbell. 1991. Recent variations in Arctic and Antarctic sea-ice covers. Nature, 352(6330), 33-36.

Gloersen, P. and D.J. Cavalieri. 1986. Reduction of weather effects in the calculation of sea ice concentration from microwave radiances. 7. Geophys. Res., 91(C3), 3913-3919.

Gloersen, P., W.J. Campbell, D.J. Cavalieri, J.C. Comiso, C. L. Parkinson, and H.J. Zwally. 1992. Arctic and Antarctic sea ice, 1978-1987: satellite passive microwave observations and analysis. Washington, DC, National Aeronautics and Space Administration. (NASA SP-511.)

Parkinson, C. L., J. C. Comiso, H.J. Zwally, D.J. Cavalieri, P. Gloersen and W.J. Campbell. 1987. Arctic sea ice, 1973-1976: satellite passive-microwave observations. Washington, DC, National Aeronautics and Space Administration. (NASA SP-489.)

Zwally, H.J., J.C. Comiso, C.L. Parkinson, W.J. Campbell, F.D. Carsey and P. Gloersen. 1983. Antarctic sea ice, 1973-1976: satellite passive-microwave observations. Washington, DC, National Aeronautics and Space Administration. (NASA SP-459.)

The accuracy of references in the text and in this list is the responsibility of the authors, to whom queries should be addressed. 